(I) Annuaire pour l'an 1940

Publié par le Bureau des Longitudes. Avec des Notices scientifiques. Pp. viii $+550+\mathrm{Al} 6+\mathrm{B} 26+$ C54. (Paris : Gauthier-Villars, 1940.) 25 francs.

(2) The Observer's Handbook for 1940

(Thirty-second Year of Publication.) Pp. 80. (Toronto: Royal Astronomical Society of Canada, 1939.)

(1) MONGST the various handbooks published each year mention may be made of the "Annuaire", published by the French Bureau of Longitudes, and "The Observer's Handbook" of the Royal Astronomical Society of Canada. The former has a long history, being first published in 1795 , when it contained about eighty pages. The present comprehensive volume contains 550 pages besides an appendix. Its contents are grouped under the following headings : (1) Calendar for 1940 including astronomical data, tide predictions, etc. ; (2) Earth - geodesy, meteorology, terrestrial magnetism, time determination; (3) Astronomy - star charts, minor planets, comets, stellar spectra, etc.; (4) Units of measurement; (5) Physical and chemical data. Two special articles are appended: "L'Espace Interstellaire", by M. Chas. Fabry (being the George Darwin Lecture of the Royal Astronomical Society for 1938), and "Le Bureau Internationale de l'Heure", by M. A. Lambert.

(2) "The Observer's Handbook" is purely an astronomical handbook intended more especially for the use of the non-professional. Besides providing a journal of astronomical events from day to day (datum, 75th meridian civil time), there are several useful tables. One of these gives the principal facts regarding 259 stars brighter than apparent magnitude $3 \cdot 51$. Another gives the position and type of the star clusters and nebulæ contained in Messier's catalogue compiled in 1781. A rough chart directs attention to the remarkable grouping of bright planets which occurred on February 28 (see also NATURe, January 27, p. 146). The transit of Mercury across the sun's disk on November 11-12 receives notice as it will be partly visible in Canada,.

\section{Structure of Algebras}

By Prof. A. Adrian Albert. (American Mathematical Society, Colloquium Publications, Vol. 24.) Pp. $\mathrm{xi}+210$. (New York: American Mathematical Society, 1939.) 4 dollars.

NOT only the contents, but even the title of this 1 book may puzzle many good mathematicians of the older school. Algebra seemed to be a stereotyped subject which started with substitution, addition, subtraction, multiplication and division, had a great deal about equations, progressions, the binomial, exponential and logarithmic theorems, and then, after some chapters on miscellaneous topics, concluded with determinants and the theory of equations. There were a few pages headed the "Fundamental Laws of Algebra", which were generally felt to be an unnecessary statement of the obvious. At one time invariants came into fashion, and were spoken of as the "Modern Higher Algebra".

Now recently books have appeared having scarcely anything in common with older books except their titles. In Prof. Albert's "Modern Higher Algebra" (Cambridge University Press, 1938) the subjects dealt with are groups, rings, integral domains, fields and matrices. The subject of matrices, so important in quantum mechanics and factor analysis, is here taken as the starting point for the discussion of abstract entities satisfying the same laws as certain matrices. These entities are known as linear associative algebras. In the book under review a more advanced treatment of these algebras is given, including recent advances due to R. Brauer, H. Hasse, E. Noether, and the author himself.

\section{Medical Sciences}

Bergey's Manual of Determinative Bacteriology

A Key for the Identification of Organisms of the Class Schizomycetes. By David H. Bergey, Robert S. Breed, E. G. D. Murray and A. Parker Hitchens. Fifth edition. Pp. xi+1032. (London: Baillière, Tindall \& Cox, 1939.) $45 s$.

IN the sixteen years that have elapsed since the first publication of Bergey's "Manual" the work has undergone considerable change and amplification ; many of the mistakes that detracted from the earlier editions have been rectified and the present edition, under its capable board of editors, shows a marked advance on its predecessors.

The assistance of experts has been made use of in the revision of certain groups-particularly in the realm of serology - and for the first time attention is directed to the serological grouping and typing of the hæmolytic streptocoeci and to the work of the Salmonella Sub-committee of the Nomenclature Committee of the International Association of Microbiologists on the taxonomy and classification of the genus Salmonella. In the latter connexion be it observed, however, that the organism of typhoid fever is still placed in the genus Eberthella instead of in the genus Salmonella, where by virtue of its serological characters it most certainly belongs, and that notwithstanding the serological identity of Salmonella pullorum and Salmonella gallinarum the latter is taken out of the genus Salmonella and placed in the genus Shigella, along with the dysentery bacteria. Furthermore, no mention is made of the significant serological relationship of the organism of tularæmia with the members of the genus Brucella and it is relegated to the genus Pasteurella on purely negative characters. The curious statement is made, moreover, that this widespread disease is only known in North America.

Strange omissions are still noticeable : one searches in vain for description of the organisms of pleuropneumonia and contagious agalactia and the other members of the group - this in spite of a considerable and growing literature on the subject. No doubt these and other questions will be considered at some future date and necessary action taken by the recently appointed Judicial Commission of the Nomenclature Committee of the I.A.M., of which the editor-in-chief of the "Manual" is one of the jointsecretaries. 